\title{
Magnitude and temporal trends in avoidable blindness in children (ABC) in India
}

\section{Venkata S Murthy Gudlavalleti}

Director, Indian Institute of Public Health, Hyderabad \& Professor, Public Health Eye Care \& Disability, Department of Clinical Research, Faculty Infectious \& Tropical Diseases, London School of Hygiene \& Tropical Medicine, London, UK.

\section{Corresponding author:}

Dr. Venkata S Murthy Gudlavalleti

ANV Arcade, 1 Amar Cooperative Society, Kavuri Hills, Madhapur, Hyderabad, Telangana State - 500033

Tel: 040-49006001

Fax: 040-49006060

Email: murthy.gvs@iiphh.org

Conflict of interest: None

Funding source: None 


\section{Abstract \\ Background}

The World Health Organization estimates that 19 million children are visually impaired among whom, 1.4 million are blind.

Childhood blindness is an excellent indicator of the state of child health and primary care services in a country.

Childhood blindness is important not just due to the number of children blind but also because the number of years that the surviving child has to live with blindness (blind years lived). Childhood blindness is next only to adult cataract in terms of the number of blind person years lived.

Under-five mortality rates have been used as a proxy measure to compute the prevalence of childhood blindness in low and middle-income countries due to limitations of other methods of data collection. In India, it is estimated that there are 0.8 blind for 1000 children.

\section{Objective}

Review the magnitude and temporal trends in avoidable blindness in children, with reference to the Indian context

\section{Methods}

Review of published literature on blindness and visual impairment in children from India and other countries in the South Asia region were assessed and observations compiled.

\section{Results}

Whole globe lesions, corneal scarring, retinal pathology and afflictions of the lens are important anatomical sites in children. Causes operating in childhood and hereditary causes are important in etiology of childhood blindness. In $38.2 \%-68.4 \%$ across the region a specific cause of blindness could not be identified in South Asia.

\section{Conclusions}

The proportion of blindness that can be prevented or treated (avoidable) in children is less than 50\%. Therefore a comprehensive eye care system needs to be in place to cater to the needs of children with avoidable and those with 
incurable blindness. Early detection and prompt management are critical for success of programs targeting avoidable blindness in children.

\section{Keywords}

Blindness; Childhood; India; Prevalence; Vision disability 


\section{Background}

The World Health Organization (WHO) defines childhood blindness and visual impairment as best corrected visual acuity of $<3 / 60$ (blindness) and $<6 / 60$ to $3 / 60$ (visual impairment) in the better eye among those aged 0-15 years [1]. WHO estimates of the global magnitude of childhood blindness suggest that there were 1.42 million children blind and 17.52 million children with moderate or severe visual impairment. Thus 18.94 million children are visually impaired [2]. The global estimates show that childhood blindness is responsible for $3.64 \%$ of all blindness in the recent past [2]. These numbers do not capture the critical importance of childhood blindness because the number of years that a child lives with blindness compared to an adult is far more, which is why blind children deserve special attention. This has led to the concept of 'blind years' and 'blind years saved' [1]. It has been computed that childhood blindness results in 11.2 million blind person years as compared with 22.5 million blind person-years for age-related cataracts and 5.5 million blind person-years for glaucoma in India [3]. Some authors have highlighted that restoring the sight of one child blind from cataract is equivalent to restoring the sight of 10 older adults blind from cataract [1].

Loss of vision has a significant impact on the affected child's psychological, educational and socio-economic consequences spanning not only the childhood years but the years beyond too [4]. Visual impairment in children can present either as an isolated impairment or else it could be accompanied by other sensory or motor impairments.

Another important aspect that needs attention is that unlike overall causes of blindness where $80 \%$ are 'avoidable' (either preventable or treatable) [1], in children less than $50 \%$ of the causes are avoidable [5]. It is for this reason that childhood blindness is one of the five priority areas for augmented interventions that have been flagged up in the Vision2020: The Right to Sight initiative [6]. This also means that the proportion needing rehabilitative services are significantly higher in blind children compared to adults.

Childhood blindness is an excellent indicator of the state of child health and primary care services in a country.

Studies have shown that the prevalence of childhood blindness is associated with socio-economic development of a country and the under-five mortality rate [5]. Using under-five mortality rates as a proxy measure, it has been possible to estimate the prevalence of childhood blindness across different regions of the world [7]. 


\section{Measuring Blindness and Visual Impairment in Children}

Measuring visual acuity in children is a difficult proposition [7]. As blindness in children is relatively rare, accurate prevalence data are difficult to obtain, because very large samples are required for population-based prevalence surveys [5]. In addition, many of the causes of childhood blindness are also the causes of mortality in children and this leads to increased mortality of blind children either from the systemic complications of the blindness-causing condition or lack of adequate parental care and support [5]. It is therefore believed that the estimates of prevalence grossly underestimate the extent of the true incidence of childhood blindness [5]. This has resulted in other methods being used to assess blindness. In high income countries, population-based registers for visual impairment are used to compute the prevalence and magnitude of blindness in children [8]. Childhood vision screening and active surveillance have also been adopted in such countries [9]. In the low and middle income countries, alternative affordable methods have been used. These include the use of under-five mortality rates as a useful proxy measure for estimating childhood blindness, data from community-based rehabilitation (CBR) programs and through use of key informants from the community after a short orientation [10]. The key informant method has been used extensively in Bangladesh [10,11], Zambia [12], Malawi[13] and Nigeria [14].

\section{Magnitude in India}

An estimated 19 million children are visually impaired worldwide of whom 1.4 million are blind [2,4]. In high income countries, the annual cumulative incidence of severe visual impairment and blindness is estimated to be 6/10,000 children by age of 15 years [4]. Such data is not available for low and middle income countries (LMIC) like India where socio-economic development and under-five mortality rates have been used to compute a prevalence of $0.3 / 1000$ children in high income countries to 0.6/1000 in middle, 0.9/1000 in low income and 1.2/1000 in very low income countries [7]. The National Program for Control of Blindness uses an estimate of 0.8/1000 children as a reasonable projection for childhood blindness India [15].

Population-based data on childhood blindness is available only from a few studies in India and the neighboring countries in South Asia (Table 1). Estimates of blind children vary from $0.5 / 1000$ children to $1.06 / 1000$ children in India [3,16-22]. However the definition of blindness (presenting vision versus best corrected vision), method of collecting data (single stage where all children are examined in the community as against two-stage process where the first vision examination is done in the community and a detailed examination at a base hospital after referral) and 
the age group covered are not uniform across the studies and therefore comparison of estimates is strictly not warranted. In some studies the primary purpose was not the estimation of childhood blindness but the estimates could be computed from the data.

\section{Causes of Childhood blindness}

The two commonest sources for information on causes of blindness in children are population-based surveys and an assessment of children residing in schools for the blind. The causes vary based on the source. Population-based surveys show that refractive errors and amblyopia are important causes of childhood blindness $[3,16]$ but the picture which emerges from inmates of schools for the blind is very different. A series of studies have been done in South Asia at schools for the blind over the last three decades and these have all used a standardized reporting format which was designed by the WHO [23]. This allows temporal trends to be computed and for comparisons to be made across regions and time periods. Data from the schools for the blind have a limitation that it is only a small segment of the population of children who go blind, that would be admitted to such institutions. This is because most of these institutions are located in urban areas and parents may not be comfortable to send their children, especially the girls to a distant location. Also as was mentioned earlier, a significant proportion of blind children, do not survive and therefore would not be represented in these institutions. The other limitation is that the event leading to visual loss generally would have occurred some years ago and recall bias would be encountered. One therefore sees that the exact location or the specific etiology causing vision loss may remain undetermined. Despite these limitations, data on causes of blindness from schools/institutions for the blind are the major source on causes of blindness in children.

The WHO format has been designed to record the causes of visual loss with an emphasis on preventable and treatable causes so that appropriate control measures can be planned and implemented [23]. The format captures information on the anatomical site affected and the etiology of the visual loss and data is also presented for both domains.

A review of studies from the schools for the blind in South Asia, reveal significant variations across regions/countries as well as over time in anatomical site of blindness [24-34]. Whole globe lesions seem to be higher in India compared to the neighboring countries in South Asia and this seems to have increased over time (Table 2). Microphthalmos, anophthalmos and phthisis are the commonest whole globe afflictions in the region. Corneal conditions were also recorded as a leading cause of blindness across the region. In the past, corneal scarring was 
recognized as the single most important cause of childhood blindness [5]. Recent studies in India and Sri Lanka document a decreasing trend in corneal blindness. Evidence from India show that from a quarter of all blindness was attributed to corneal conditions earlier which is now down to around 10\% [24-26; 29,30,33]. Staphyloma and corneal scaring were the commonest corneal conditions recorded. The lens and retina were other important sites causing blindness. Studies from India revealed a low proportion of blindness due to Retinopathy of Prematurity (ROP) [26,27,30], while more than 10\% was attributed to ROP in Sri Lanka [32]. Globally ROP is recognized as a leading cause of childhood blindness especially in rapidly emerging economies [5].

Determination of the etiological cause in studies in South Asia showed that no etiology could be identified in 38.2\% to $68.4 \%$ across the region (Table 3) [24-28; 30-34]. This is because of the high degree of recall bias in such an assessment. Causes operating in childhood and hereditary causes were the predominant attributable causes of childhood blindness. A low proportion of childhood causes (2.6\%) and a high proportion of hereditary causes (37.5\%) observed in Sri Lanka is a good indicator of what India can expect with improving child survival and primary health care programs [32]. Vitamin A deficiency and measles were the commonest childhood causes documented and with improved health care services and access a major reduction in these conditions is imminent in India also.

\section{Implications of recent data on childhood blindness}

In South Asia it has been observed that the proportion of avoidable causes of childhood blindness varies between $28.8 \%-69.2 \%$ [24-34]. Studies over the past decade in India document that avoidable causes are responsible for less than a third of childhood blindness [29,30,33]. Only one study from North East India shows that the proportion avoidable is 50\% [27] (Table 4). Earlier studies in India (Table 4) showed a much higher prevalence of avoidable causes compared to the recent studies. This temporal change reflects success of primary health care interventions like immunization and supplementation programs which have made an impact on blindness attributable to vitamin A deficiency, measles, harmful traditional practices, rubella etc. This trend is supported by evidence which shows that there has been a significant reduction of vitamin A deficiency in India over the past few decades as shown by the reduction in the prevalence of Bitot's spots (which is indicative of vitamin A deficiency) from $1.8 \%$ among preschool children in 1975 to $0.2 \%$ in 2012 [35]. 
Over the past decade, both infant mortality rate and under-five mortality rate in India have decreased significantly [36]. Since under-five mortality has been found to be associated with childhood blindness rates, this should impact the magnitude of childhood blindness. Under-five mortality has reduced by 67\% between 2005 and 2015 as shown by the National Family Health Surveys [36]. Concerted action was initiated to expand services for sick and preterm newborn infants in India which is reflected in the decreasing child mortality rates [37]. At the same time there has been an increasing prevalence of preterm births which brings in new challenges. An estimated 15 million babies are born preterm ( $<37$ weeks of completed gestational age) each year and at least 32 million babies are small for gestational age [38]. In India, it is estimated that there were 3.52 million preterm births in 2010 [38]. The improved neonatal care services have resulted in better survival of pre-terms due to improved respiratory support, including the use of oxygen. ROP is especially sensitive to the quality of neonatal care, including appropriate, well-monitored oxygen [39]. India accounted for $10 \%$ of the worldwide estimate of blindness and visual impairment due to ROP in 2010 [38]. It has been stated that, unless scale-up of neonatal services are coupled with improvements in implementation of standards for high quality care and detection and treatment of ROP, the number of children surviving preterm birth with visual impairment secondary to ROP will continue to increase [39].

\section{The Way Forward}

Childhood blindness is a condition where an integrated care approach is imperative. The mantra for success is forging partnerships between pediatricians and child care teams on the one hand and ophthalmologists and the eye care teams on the other. Early detection and referral will be from a pediatrician or primary care setting while a multidisciplinary approach coordinated by an ophthalmologist is needed to manage the underlying cause of visual impairment and to optimize the child's development and social inclusion.

Further investments in neonatal care services and practices will yield excellent returns. India is now one of several LMIC experiencing the 'third epidemic' of blindness due to ROP [37]. Blindness due to ROP can be prevented by following an evidence-based screening protocol, detecting ROP in pre-threshold stage and providing time-bound treatment [37]. This approach has to be rigorously followed if blindness free survival of preterm babies is to be ensured in the country. Efforts are being made to build capacity for early screening of ROP at sick newborn care units and timely management to prevent visual impairment. The Queen Elizabeth Diamond Jubilee Trust is supporting the development of innovative approaches for screening and management of ROP in 5 states in India. If this approach is successful it can be scaled up to the rest of the country and may be useful for other LMICs also. 
Primary health care is critical to the reduction of the preventable causes of childhood blindness. Improving coverage rates of immunization, introduction of the rubella vaccine, quality antenatal care provision and attention to nutrition will have an even bigger impact on childhood blindness.

With reduction of preventable causes, there will be a relative increase in the proportion of unavoidable causes of childhood blindness. These children need rehabilitative support including affordable and acceptable low vision devices. Therefore comprehensive eye care services which include a gamut of preventive, promotive, curative and rehabilitative interventions and innovations in detection and service delivery are the need of the future. Augmenting the available infrastructure for pediatric eye care at the specialty level is also important so that case detection is matched with appropriate services. Creating a demand without adequate service delivery networks is detrimental in the long run. Some people have been advocating for universal eye screening. Caution is required before such a step is taken as the currently available resources including human resource capacity and infrastructure needs to be scaled up in the first instance. The WHO has set norms for low vision services and pediatric eye care units for every 10 million population. Such norms need to be enforced to achieve pragmatic reduction in avoidable blindness in children and provide services for those in whom blindness and visual impairment could not be prevented or treated. 


\section{References}

1. Gilbert C,Foster A. Blindness in children: control priorities and research opportunities. Br J Ophthalmol $2001 ; 85: 1025-1027$

2. Pascolini D, Mariotti SP. Global estimates of visual impairment: 2010. Br J Ophthalmol 2012; 96: 614-618.

3. Dandona L, Williams JD, Williams BC et al. Population-based assessment of childhood blindness in southern India. Arch Ophthalmol 1998; 116:545-546.

4. Solebo AL, Rahi J. Epidemiology, aetiology and management of visual impairment in children. Arch Dis Child 2014; 99: 375-9.

5. Gilbert C, Foster A. Childhood blindness in the context of Vision2020: The Right to Sight. Bull World Health Organ 2001; 79:227-232.

6. Pizzarello L, Abiose A, Ffytche T et al. VISION 2020: The Right to Sight - A global initiative to eliminate avoidable blindness. Arch Ophthalmol 2004; 122: 615-620

7. Gilbert C. Changing challenges in the control of blindness in children. Eye 2007; 21: 1338-1343.

8. Bodeau-Livinnec F, Surman G, Kaminski M, Wilkinson AR, Kurinczuk JJ. Recent trends in visual impairment and blindness in the UK. Arch Dis Child 2007; 92: 1099 - 104.

9. Rahi JS, Cumberland PM, Peckham CS. Improving detection of blindness in childhood: The British Childhood Vision Impairment study. Pediatrics 2010; 126: 3895-903.

10. Muhit MA, Shah SP, Gilbert CE, Hartley SD, Foster A. The key informant method: a novel means of ascertaining blind children in Bangladesh. Br J Ophthalmol 2007; 91: 995-9.

11. Husain L. Using the key informant method to investigate childhood blindness related to vitamin A deficiency in six rural districts in rural sub-districts in Bangladesh. J Community Eye Health 2007; 20: 7-8

12. Chipalo-Mutati G. A survey of childhood blindness in three schools for the blind in Zambia. J Community Eye Health 2007; 20: 7

13. Kalua K. Use of key informants in determining the magnitude and causes of childhood blindness in Chikwawa district, southern Malawi. J Community Eye Health 2007; 20: 8 
14. Muhammad N, Maishanu NM, Jabo AM, Raiu MM. Tracing children with blindness and visual impairment using the key informant survey in a district of North-Western Nigeria. Middle East African J Ophthalmol 2010; 17: 330-334.

15. Jose R, Sachdeva S. School eye screening and the National Program for the control of blindness. Indian Pediatrics 2009; 46:205-208.

16. Nirmalan PK, Vijayalakshmi P, Sheeladevi S et al. The Kariapatti pediatric eye evaluation project:baseline ophthalmic data of children aged 15 years or younger in southern India. Am J Ophthalmol 2003; 136 : 703 709.

17. Dandona R, Dandona L. Childhood blindness in India: a population based perspective. Br J Ophthalmol 2003; 87: 263-265.

18. Murthy GV, Gupta SK, Ellwein LB et al. Refractive errors in children in an urban population in New Delhi. Invest Ophthalmol Vis Sci 2002; 43: 623-631.

19. Dandona R, Dandona L, Srinivas M et al. Refractive error in children in a rural population in India. Invest Ophthalmol Vis Sci 2002; 43:615-622

20. Dorairaj SK, Bandrakalli P, Shetty C et al. Childhood blindness in a rural population of southern India: prevalence and etiology. Ophthalmic Epidemiol 2008; 15: 176-82.

21. Kemmanu V, Hegde K, Giliyar SK et al. Prevalence of childhood blindness and ocular morbidity in a rural pediatric population in southern India: The Pavagada pediatric eye disease study-1. Ophthalmic Epidemiol $2016 ; 23: 185-92$.

22. Murthy GV, Mactaggart I, Mohammad M et al. Assessing the prevalence of sensory and motor impairments in childhood in Bangladesh using key informants. Arch Dis Child 2014; 99:1103-8

23. Gilbert C, Foster A, Negrel AD, Thylefors B. Childhood blindness: a new form for recording causes of visual loss in children. Bulletin World Health Organ 1993; 71: 485-489

24. Rahi JS, Sripathi S, Gilbert CE, Foster A. Childhood Blindness in India: Causes in 1318 Blind School Students in nine states. Eye 1995; 9: 545-550

25. Hornby SJ, Adolph S, Gothwal VK, Gilbert CE, Dandona L, Foster A. Evaluation of children in six blind schools of Andhra Pradesh. Indian J Ophthalmol 2000; 48: 195-200 
26. Titiyal JS, Pal N, Murthy GVS, Gupta SK, Tandon R, Vajpayee RB, Gilbert CE. Causes and temporal trends of blindness and severe visual impairment in children in schools for the blind in North India. Br $\mathbf{J}$ Ophthalmol 2003; 87: 941-945

27. Bhattacharjee H, Das K, Borah RR, Guha K, Gogate P, Purukayastha S, Gilbert CE. Causes of childhood blindness in the northeastern States of India. Indian J Ophthalmol 2008; 56:495-9

28. Muhit MA, Shah SP, Gilbert CE, Foster A. Causes of severe visual impairment and blindness in Bangladesh: a study of 1935 children. Br J Ophthalmol 2007; 91: 1000-1004

29. Gogate P, Deshpande M, Sudrik S, Taras S, Kishore H, Gilbert CE. Changing pattern of childhood blindness in Maharashtra, India. Br J Ophthalmol 2007; 91:8-12

30. Gogate P, Kishore H, Dole K, Shetty J, Gilbert C, Ranade S, Kumar M,Srihari, Deshpande M. The pattern of childhood blindness in Karnataka, South India. Ophthalmic Epidemiol 2009; 16: 212-217.

31. Muecke J, Hammerton M, Aung YY, Warrier S, Kong A, Morse A, Holmes M, Yapp M, Hamilton C, Selva D. A survey of visual impairment and blindness in children attending seven schools for the blind in Myanmar. Ophthalmic Epidemiol 2009; 16: 370-377

32. Gao Z, Muecke J, Edussuriaya K, Dayawansa R, Hammerton M, Kong A, Sennanayake S, Senaratne T, Marasinghe N, Selva D. A survey of severe visual impairment and blindness in children attending thirteen schools for the blind in Sri Lanka. Ophthalmic Epidemiol 2011; 18: 36-43

33. Krishnaiah S, Rao BS,Narasamma KL, Amit G. A survey of severe visual impairment in children attending schools for the blind in a coastal district of Andhra Pradesh in South India. Eye 2012; 26:1065-1070

34. Shrestha JB, Gnyawali S, Upadhyay MP. Causes of blindness and visual impairment among students in integrated schools for the blind in Nepal. Ophthalmic Epidemiol 2012; 19: 401-406

35. Kapil U, Gupta A. Low quality scientific evidence for the continuation of universal vitamin A supplementation among under 5 children in India. Indian J Public Health 2016; 60: 176-80

36. International Institute for Population Sciences. National Family Health Survey-4 2015-16: India Fact Sheet. Government of India, Ministry of Health \& Family Welfare, New Delhi, India, 2016: 1-6. http://rchiips.org/nfhs/pdf/NFHS4/India.pdf. Accessed 20 $0^{\text {th }}$ March 2017

37. Deorari A, Gilbert C. Controlling visual loss from retinopathy of prematurity in India. Indian Pediatrics 2016; 53; Supple 2: S73-S75 
38. Blencowe H, Cousens S, Oestergaard MZ, Chou D, Moller AB, Narwal R, et al. National, regional, and worldwide estimates of preterm birth rates in the year 2010 with time trends since 1990 for selected countries: A systematic analysis and implications. Lancet. 2012;379:2162-72.

39. Blencowe H, Moxon S, Gilbert C. Update on Blindness due to Retinopathy of Prematurity globally and in India. Indian Pediatr2016; 53, Supplement 2: S89-92. 
Table I

Prevalence of Childhood Blindness

\begin{tabular}{|c|c|c|c|c|c|c|c|c|}
\hline Location & $\begin{array}{l}\text { Age } \\
\text { Group }\end{array}$ & $\begin{array}{l}\text { Sample } \\
\text { (n) }\end{array}$ & Year & Method & $\begin{array}{l}\text { Visual } \\
\text { Acuity }\end{array}$ & $\begin{array}{l}\text { Visual } \\
\text { Acuity } \\
\text { cut-off }\end{array}$ & $\begin{array}{l}\text { Prevalence } \\
\text { per } 1000\end{array}$ & Reference \\
\hline $\begin{array}{l}\text { West Godavari } \\
\text { district, Andhra } \\
\text { Pradesh }\end{array}$ & $\begin{array}{l}\leq 15 \\
\text { years }\end{array}$ & 113,514 & 1996 & Survey & $\mathrm{BCVA}^{\dagger}$ & $<3 / 60$ & 0.65 & 3 \\
\hline $\begin{array}{l}\text { Kariapatti, } \\
\text { Tamilnadu }\end{array}$ & $\begin{array}{l}\leq 15 \\
\text { years }\end{array}$ & 10,605 & 2000 & $\begin{array}{l}2 \text { stage } \\
\text { survey }\end{array}$ & BCVA & $<3 / 60$ & 0.62 & 16 \\
\hline Andhra Pradesh & $\begin{array}{l}\leq 15 \\
\text { years }\end{array}$ & 2861 & 2001 & Survey & $\mathrm{PVA}^{*}$ & $<3 / 60$ & 1.0 & 17 \\
\hline New Delhi, India & $\begin{array}{l}5-15 \\
\text { years }\end{array}$ & 5950 & 2001 & Survey & BCVA & $<6 / 60$ & 0.5 & 18 \\
\hline Mahbubnagar, AP & $\begin{array}{l}7-15 \\
\text { years }\end{array}$ & 3994 & 2001 & Survey & BCVA & $<6 / 60$ & 1.3 & 19 \\
\hline Karnataka & $\begin{array}{l}\leq 15 \\
\text { years }\end{array}$ & 13,241 & 2004 & $\begin{array}{l}2 \text { stage } \\
\text { survey }\end{array}$ & BCVA & $<3 / 60$ & 1.06 & 20 \\
\hline Tumkur, Karnataka & $\begin{array}{l}\leq 15 \\
\text { years }\end{array}$ & 23,100 & 2006 & $\begin{array}{l}2 \text { stage } \\
\text { survey }\end{array}$ & BCVA & $<3 / 60$ & 0.8 & 21 \\
\hline $\begin{array}{l}\text { Rajshahi, } \\
\text { Bangladesh }\end{array}$ & $\begin{array}{l}\leq 18 \\
\text { years }\end{array}$ & 8120 & 2013 & Survey & PVA & $<3 / 60$ & 0.5 & 22 \\
\hline
\end{tabular}


Table II: Anatomical Site of Affection in blind children in schools for the blind

\begin{tabular}{|c|c|c|c|c|c|c|c|c|c|c|c|}
\hline Site & $\begin{array}{l}9 \text { States, } \\
\text { India }\end{array}$ & AP & Delhi & NE India & Bangladesh & Maharashtra & Karnataka & Myanmar & $\begin{array}{l}\text { Sri } \\
\text { Lanka }\end{array}$ & AP & Nepal \\
\hline Reference & 24 & 25 & 26 & 27 & 28 & 29 & 30 & 31 & 32 & 33 & 34 \\
\hline Year & 1993 & 1999 & 2001 & 2004 & 2005 & 2005 & 2006 & 2007 & 2009 & 2009 & 2011 \\
\hline Examined & 1318 & 291 & 650 & 376 & 1935 & 1985 & 1179 & 208 & 206 & 113 & 778 \\
\hline Whole Globe & 25.3 & 20.2 & 27.4 & 31.8 & 13.1 & 46.3 & 44.9 & 19.2 & 18.3 & 41.4 & 16.7 \\
\hline Cornea & 26.4 & 24.3 & 21.7 & 36.4 & 26.6 & 11.7 & 7.2 & 43.6 & 7.8 & 8.1 & 22.8 \\
\hline Lens & 12.3 & 7.9 & 10.9 & 10.9 & 32.5 & 6.0 & 14.1 & 14.4 & 10.9 & 9.9 & 17.6 \\
\hline Retina & 20.7 & 31.1 & 15.1 & 5.8 & 12.7 & 11.2 & 20.3 & 7.4 & 35.9 & 18.9 & 18.4 \\
\hline Optic Nerve & 5.9 & 4.9 & 10.6 & 5.4 & 8.0 & 4.6 & 4.4 & 4.0 & 10.9 & 5.4 & 8.7 \\
\hline Uvea & 5.8 & 3.4 & 8.8 & 2.3 & 2.0 & 1.5 & 0.3 & 2.5 & 2.6 & 4.5 & 5.0 \\
\hline Glaucoma & 2.6 & 6.7 & 4.9 & 4.3 & 4.3 & 1.6 & 1.9 & 7.4 & 4.1 & 8.1 & 8.1 \\
\hline Others & 0.9 & 1.5 & 0.8 & 3.1 & 1.0 & & 10.5 & 3.0 & 8.8 & 10.8 & 2.7 \\
\hline
\end{tabular}


Table III: Etiological Classification of Causes of Blindness in South Asia

\begin{tabular}{|c|c|c|c|c|c|c|c|c|c|c|}
\hline Site & $\begin{array}{l}9 \text { States, } \\
\text { India }\end{array}$ & AP & Delhi & NE India & Bangladesh & Karnataka & Myanmar & $\begin{array}{l}\text { Sri } \\
\text { Lanka }\end{array}$ & AP & Nepal \\
\hline Reference & 24 & 25 & 26 & 27 & 28 & 30 & 31 & 32 & 33 & 34 \\
\hline Year & 1993 & 1999 & 2001 & 2004 & 2005 & 2006 & 2007 & 2009 & 2009 & 2011 \\
\hline Examined & 1318 & 291 & 650 & 376 & 1935 & 1179 & 208 & 206 & 113 & 778 \\
\hline Hereditary factors & 22.9 & 34.8 & 13.4 & 7.0 & 15.0 & 44.1 & 11.9 & 37.5 & 17.1 & 27.9 \\
\hline $\begin{array}{l}\text { Intrauterine } \\
\text { factors }\end{array}$ & 1.8 & 0.4 & 0.9 & 1.6 & & 4.8 & 4.5 & 2.1 & 0.9 & 2.6 \\
\hline Perinatal factors & 1.4 & 2.6 & 1.2 & 1.2 & & 1.1 & 6.9 & 14.0 & 5.4 & 1.5 \\
\hline Childhood factors & 27.9 & 24.0 & 28.0 & 38.4 & 27.9 & 8.6 & 33.2 & 2.6 & 8.1 & 22.0 \\
\hline Unknown etiology & 46.0 & 38.2 & 56.5 & 51.9 & 41.4 & 41.3 & 43.6 & 43.8 & 68.4 & 46.0 \\
\hline
\end{tabular}


Table IV: Avoidable causes of blindness among children in South Asia including India

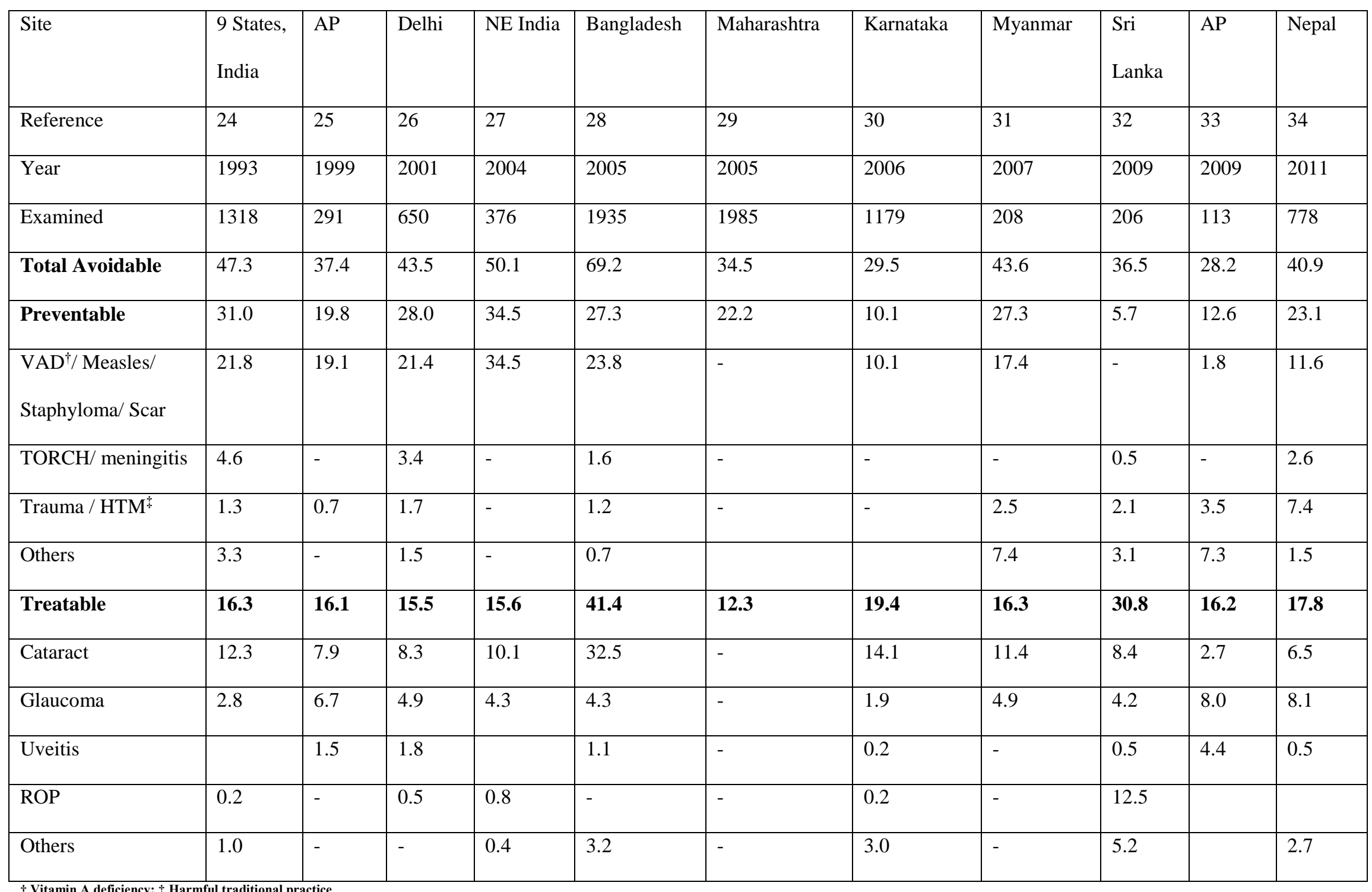

$\doteqdot$ Vitamin A deficiency; $\ddagger$ Harmful traditional practice 